\title{
Humboldt's enigma: what causes global patterns of mountain biodiversity?
}

Authors: Carsten Rahbek ${ }^{1,2 * \dagger}$, Michael K. Borregaard ${ }^{1} \dagger$, Robert K. Colwell ${ }^{1,3,4}$, Bo Dalsgaard ${ }^{1}$, Benjamin G. Holt ${ }^{1}$, Naia Morueta-Holme ${ }^{1}$, David Nogués-Bravo ${ }^{1}$, Robert J. Whittaker ${ }^{1,5}$, Jon Fjeldså ${ }^{1}$.

\section{Affiliations:}

${ }^{1}$ Center for Macroecology, Evolution and Climate, GLOBE Institute, University of Copenhagen, Denmark.

${ }^{2}$ Department of Life Sciences, Imperial College London, Ascot SL5 7PY, UK.

${ }^{3}$ Department of Ecology and Evolutionary Biology, University of Connecticut, Storrs, CT 06269, USA.

${ }^{4}$ University of Colorado Museum of Natural History, Boulder, CO 80309, USA.

$20{ }^{5}$ School of Geography \& the Environment, University of Oxford, South Parks Rd, OX1 3QY, UK.

*Correspondence to: crahbek@snm.ku.dk.

$\dagger$ These authors contributed equally.

\begin{abstract}
:
Mountains contribute disproportionately to the terrestrial biodiversity of Earth, especially in the tropics, where they host hotspots of extraordinary and puzzling richness. With about $25 \%$ of all land area, mountain regions are home to more than $85 \%$ of the world's species of amphibians, birds, and mammals, many entirely restricted to mountains. Biodiversity varies dramatically among these regions. Together with the extreme species richness of some tropical mountains, this variation has proven challenging to explain under traditional, climatic hypotheses. However, the complex climatic characteristics of rugged mountain regions differ fundamentally from lowland regions, likely playing a key role in generating and maintaining diversity. With ongoing global changes in climate and land use, the role of mountains as refugia for biodiversity may well come under threat.
\end{abstract}


One Sentence Summary: Mountains are pivotal to the terrestrial biodiversity of Earth, yet the causes of this richness remain a riddle of ecology and evolution: Humboldt's enigma. 
When Alexander von Humboldt set sail in 1799 on a five-year, 8,000 km voyage of scientific discovery through Latin America, he aimed to collect data to assemble a unified theory of the natural world. While we are still in search of such a theory, Humboldt's work revolutionized our thinking about what determines the distribution of life. His journey through the Andes Mountains, captured by his famous vegetation zonation figure featuring Mt Chimborazo, canonized the place of mountains in understanding Earth's biodiversity. Following in von Humboldt's footsteps, two centuries of mountain studies have revealed many of the general principles and processes that constitute biogeography, macroecology, and evolutionary biology (1), yet the quest for a unified theory for global patterns of diversity continues.

Current hypotheses for large-scale geographical patterns of species diversity fail to explain the extraordinarily high biodiversity of mountain regions, particularly in the tropics (2-5). We call this challenge "Humboldt's enigma". Here, we follow von Humboldt's focus on mountains and take a fresh look at global patterns of montane biodiversity and how they relate to variation in topography and climate. Our review is focused on biodiversity overall, illustrated with figures based on comprehensive global datasets for ca. 21,000 species of amphibians, birds, and mammals (6) and their distributions across 134 Mountain Regions of the world (7), supplemented with information on plant and insect groups for which data are available.

\section{The importance of mountain regions for global biodiversity}

Conventional wisdom has it that extensive lowland tropical forests, such as those of the vast Amazon Basin, with their lush vegetation, high biomass and complex stratification, contain unparalleled levels of biodiversity, with a world record of 942 plant species in 1 ha (8). Taking area into account, however, the extreme species spatial turnover of species in the Andes (9) makes this region more diverse at the regional scale than lowland Amazon forests, Surprisingly, compared to the slopes of the nearby Andes, the rich, lowland rainforests of the Amazon have been described as biologically impoverished for vertebrates (10-12). Meta-analyses of elevational gradients for plants and insects also show that local richness typically peaks on the slopes of mountains rather than in the lowlands $(11,13)$, when sampling intensity and area are taken into account. In their global analyses of regional-scale hotspots of plant endemism, Myers and co-workers (14) identified mountain regions as among the richest in the world.

The world's Mountain Regions, here defined to include not only mountain slopes and peaks, but also valleys and adjacent foothills (7), are indeed home to a remarkable proportion of Earth's terrestrial vertebrate species, given their relatively small area, making them hotspots of extraordinary richness (Fig. 1 and 2). Thus, Mountain Regions host roughly 87\% of the world's species of amphibians, birds and mammals, while constituting only around $25 \%$ of terrestrial land mass (excluding Antarctica), and a large number of these species are restricted (endemic) to Mountain Regions (Fig. 1 and 3).

The high concentration of species in tropical Mountain Regions has proven difficult to explain. The vast majority of studies of large-scale variation in species richness have been 
focused on non-tropical continents. These studies have found strong correlations between species richness and current (or past) climatic factors, within standardized grid cells of typically 50x50 or $100 \times 100 \mathrm{~km}(15-17)$. In contrast, the few analyses encompassing largely tropical continents show that this presumed general relationship of species richness with climate breaks down within tropical mountains, the world's richest biodiversity hotspots, with regressions leaving strong positive residuals geographically clustered within topographically complex regions (Fig. 2B) (2$4,18)$. Even in non-tropical regions, some studies have revealed positive residuals from climatebased diversity models in Mountain Regions (17). Clearly, both statistical and process-based (1920) models of large-scale patterns of species richness must take account of topography, as well as climate, to account for the small-scale diversity patterns that underlie them $(2,5,17,21-22$.

It follows that mountains either play idiosyncratic roles in continental patterns of biodiversity, or that models developed thus far are missing some vital components or processes that have not yet been identified. Solving the conundrum of the extraordinary diversity of mountains remains one of the greatest challenges for understanding global patterns in species richness.

\section{The pattern of global mountain biodiversity}

Here we take a different approach from the classic grid-cell based analyses and treat each distinct Mountain Region as an independent unit of analysis (7). Like an island, a Mountain Region may be viewed as a biogeographical unit in itself (23), with in situ speciation and extinction playing a

20 key role in building the regional species assemblage. The biodiversity of individual Mountain Regions varies dramatically at a global scale (Fig. 3). In the arctic and temperate zones, Mountain Regions typically have low species diversity, barely exceeding the richness of adjacent lowlands, and often without their own endemic species. While not all low-latitude (tropical) Mountain Regions are unusually diverse, some are exceptionally so. Not only the Andes of South America, but also the East African Highlands, the Sichuan/Yunnan mountains of Asia, and the mountains of Papua New Guinea (Fig. 2 and 3) are globally hyper-diverse (2, 3, 14, 18, 21, 22, 24). Likewise, the mountainous Atlantic Forest region of South America and the mountains of Northern Borneo and Costa Rica have been identified as mega-diverse for plants $(18,22)$. The Northern Andes and the Andean Yungas Mountain Regions encompass the most species-rich places on the planet and feature high proportions of small-ranged species (Fig. 3). The Northern Andes region supports $\sim 45,000$ plant species, of which $\sim 44 \%$ are endemic $(14,25)$.

With the exception of Atlantic Forest, all of these tropical hyperdiverse areas reach high elevations, and are characterized by spatially complex configurations of topography and climate. Within each region, local species co-occurrence is high, especially at mid-elevations, where community turnover over short distances may be greater than in any other place on the planet $(9$, 12, 26). This extraordinary diversity of both vertebrates and plants is characterized by the aggregation of many species with narrow geographical ranges in centers of endemism (Fig. $3 \mathrm{~B}$ and C), often consisting of both phylogenetically old and recent species $(1,9)$. Of the $25 \%$ of all vertebrate species with the smallest ranges, more than $54 \%$ (birds $=37 \%$, mammals $=54 \%$, 
amphibians $=83 \%$ ) are completely restricted to Mountain Regions (calculated based on distribution data in 6), making mountains epicenters for range-restricted species (Fig. 3).

\section{Global variation in diversity among Mountain Regions}

It is a well-established empirical pattern in macroecology that numbers of species generally increase with area, productivity, and topographic complexity. These correlations also hold among the Mountain Regions of the world (Fig. 4). Larger, more productive, and more topographically complex Mountain Regions not only have more species, but also more smallranged species and a greater proportion of mountain endemics. Because the rate of gain in species richness with area, productivity (controlled for area), and topographic complexity differs between low- and high-latitude Mountain Regions, the slope of the relationship increases from temperate and arctic regions, through subtropical and arid tropical regions, to the wet tropics (Fig. 4). Hence, in simplistic models, tropical regions yield positive residuals for richness, whereas high latitudes yield negative residuals, even when taking latitude into account, as we have done in Fig. 4.

Relationships of species richness with productivity may be driven by contemporary climate, while relationships with area and topographic complexity may reflect either contemporary factors or deep-time evolutionary processes, in which biome area and the equilibrium between speciation and extinction have been the key drivers of regional variation in contemporary species richness $(2,4,5,20,24)$. All exceptionally species-rich tropical Mountain Regions (Fig. 3), especially the Andes, have much higher regional diversity than expected from each of the three factors alone (Fig. 4). In this context, the high diversity of the Atlantic Forest highlands in Eastern Brazil is intriguing, as this is among the least topographically complex Mountain Regions, with a somewhat similar pattern observed for the Sichuan/Yunnan Mountains in China. High latitude Mountain Regions, such as the mountains of Alaska, have consistently lower diversity than expected from a global model based on area, productivity, and topographic complexity.

\section{Mountain climates}

30 For decades, the prevailing view was that physical conditions change with elevation in the same way as they change with increasing latitude. As gradients of species richness were often explained by ambient temperature (15-16), and mean temperature decreases with elevation (28), it followed that the elevational species richness gradient should merely be a mirror of the latitudinal gradient, with decreasing richness from lowlands towards high elevations mirroring the decrease in richness from low to high latitudes $(11,29)$. However, empirical data have shown that the elevational gradient of species richness can take many shapes, but most often take a hump-shaped pattern $(11,30)$.

As an underlying driver of ecological and evolutionary processes, climate shapes patterns of diversity in time and space within Mountain Regions, just as it does elsewhere. However, mountain climates differ in fundamental ways from those of the lowlands: 
1) Topographically complex tropical mountains may encompass a remarkable volume of different climate types, equivalent to the climate volume of vast geographical expanses within lowland regions (Fig. 5A) (31). For example, the most species-rich Mountain Region in the world, the Northern Andes, captures roughly half of the world's temperature-precipitation climate space in a relatively small region-mmore than the 12-times-larger, adjacent region of the Amazon (Fig. 5B and 5C).

2) Mountain Regions bring starkly distinct climate zones into close proximity with one another $(11,26,31,32)$. The juxtaposition of different climate zones in mountains is not only a consequence of the elevational gradient being short in absolute, planimetric terms, but also of the complexity of the gradient, which is necessarily much less gradual than the climatic turnover encountered in lowland zones. Mountains are not the idealized cones so often depicted in theoretical textbooks. In complex montane landscapes, east-facing slopes (with morning sun) may provide different conditions from adjacent, cold and foggy west-facing slopes. Shadows from neighboring mountains can drive differences among foothills with otherwise similar aspect. Deep erosion canyons with arid climates may act as dispersal barriers to species inhabiting more mesic habitats, such as the cloud forest habitat that characterizes many low-latitude mountains.

3) The temporal scale of short-term climatic oscillations-yearly and diurnal variation of temperature (33), seasonality, and growing season length - combine in ways that are unique to mountains. Day-to-day weather variation on mountaintops can be extreme, with periodically very high wind speeds. Seasonal variation in temperature, on the other hand, naturally varies with latitude, so alpine zones high on tropical mountains differ from Arctic zones in their less marked seasonality, such that diurnal and nocturnal temperatures differ more than the coldest and warmest monthly means in tropical mountains.

4) The effect of longer-term climatic oscillations is also unique in mountains. In upper montane zones, the positions of specific vegetation belts have changed markedly under Quaternary climatic shifts, often resulting in the periodic isolation of elevationally constrained populations. The result is a periodic reconfiguration of connectivity among mountain habitat patches $(1,26)$.

5) Physical parameters, such as air pressure and, consequently, oxygen availability (two factors carefully measured and recorded by von Humboldt in his travels), drop markedly and consistently with increasing elevation (32), leading to selection pressures for specific adaptations to high-mountain environments.

6) These aspects of spatial and temporal variation, as well as geophysical variation of mountains in terms of differing slopes and aspects, interact to create many rare and unique climate types (34). Some mountain climates are rare only in the sense that they are restricted to mountains, but in having many particular combinations of aspect, location, and local weather patterns, even small mountain ranges may create globally exceptional combinations of climatic factors, provided that the topography is sufficiently rugged. 
These characteristics of mountain climates are not just a simple effect of topography and elevation; they are caused by a direct interaction between mountains and the global climate system. Many tropical and temperate mountains are impacted by ocean winds in areas where warm and humid air blows onto land. These winds release humidity in the form of precipitation when the lower slopes of mountains cause clouds to form and rise, and adiabatic pressure drops. In large tropical Mountain Regions, this process typically leads to strong mist formation, where much of the humidity condenses directly onto the vegetation, creating characteristic cloud forest habitat. These cloud forests are characterized by consistently high humidity levels that may not always be well reflected in the regional record of rainfall. Mist formation plays a key role in shaping many of the vegetation types characteristic of mountains and is likely linked to the extremely high rate of spatial turnover of species composition (12).

In certain mountain climates, small valleys high in the mountains hold isolated pockets of air protected by an inversion layer, where wind and cold air act as a cap that prevents air from circulating out of the valley. Such pockets have been speculated to lead to extremely stable local climate conditions that may have enhanced survival of species through periods of past climatic change (24). Over evolutionary time, these potential refugia are thought to have been foci for adaptive differentiation of small populations and potentially for speciation (1). In spite of their potential importance for evolution, these pockets of alleged extreme stability are very small and localized, and are not picked up by coarse-grained analyses of regional climatic stability (35).

\section{Biological consequences of mountain-specific climates}

The climatic characteristics of mountains $(26,32)$ may play a key role in generating and maintaining their extraordinary levels of species diversity and probably account for most of the striking patterns illustrated in Fig. 2-4. The larger volume (per unit of planimetric area), diversity, and rarity of mountain climates promote the origination and persistence of species with small distributional ranges and small populations. By allowing the co-existence of many species with slightly different climatic niches, mountain climates may lead to a dense packing of species at local scales. The marked climate changes along steep elevation gradients are associated with a striking turnover of species over short distances, which further enhance regional diversity.

Turnover and distinctness of mountain climates over elevational gradients, so pronounced in the tropics, decrease towards temperate and boreal latitudes. This latitudinal gradient of mountain climatic distinctness was first pointed out by Janzen in 1967 in a seminal paper (36) in which he elegantly summarized this pattern as "mountain passes are higher in the tropics." Focusing on seasonal variation, he reasoned that species inhabiting tropical mountains experience a relatively smaller seasonal temperature range than species at comparable elevations at higher latitudes, and could therefore evolve narrower physiological tolerances, although thermodynamic constraints may also play a role (37). The climate regimes of tropical mountains may thus favor physiological specializations that act as effective dispersal barriers, resulting in relatively smaller elevational range sizes (36). This effect, combined with the complex mosaic of mountain microclimates, creates a patchy distribution of suitable habitats that may be isolated 
from one another, even where in close geographical proximity. This isolation could potentially reduce propagule exchange and thereby increase opportunities for speciation in allopatry.

The length of the climate gradient in mountains varies across biogeographical climate zones (Fig. 5A). A tropical mountain has more climate zones than a temperate mountain of similar height. For example, tropical mountains, based in fertile and wet equatorial lowlands and extending into climatic conditions superficially similar to those found in the Arctic, span a gradient of annual mean temperatures as large as that found in the lowlands from the Equator to the poles.

As Humboldt described (31), the layering of different climates along the elevational gradient leads to a high turnover in vegetation zones. Variation across zones in physical structure, ecological properties, and resource heterogeneity further promotes diversity in plants and other organisms. For instance, in the Andes, misty cloud forests may offer stable environments conducive to the long-term persistence of species (24), while paramos host some of the highest diversification rates on Earth, partly driven by the island-like distribution of this high-elevation vegetation zone (25).

Mountain species with narrow elevational ranges often have small local population sizes and, in large, north-south mountain ranges, geographically elongated distributions (38). Thus, during past periods of global climate change, narrow elevational distributions may have fragmented, leading to differentiation and potential speciation within mountain ranges. Relict populations may accumulate in places that remain climatically stable because of local topography (24).

\section{Concluding perspective on mountain diversity research}

It is becoming clear that the multiplicity of interacting processes that control biodiversityspeciation, movement (dispersal and range shifts), niche evolution, persistence, and extinction,impose severe limits on the explanatory potential of purely statistical models. Recent work with mechanistic simulations that explicitly model these processes on realistic topographies, driven by paleoclimate models, shows promise for understanding not only past dynamics but also future changes in mountain diversity (19-20).

The success of these models rests on the continued development of increasingly realistic global paleoclimate models on deeper time scales, with regional climate models that are sufficiently fine-grained to be applied in Mountain Regions $(20,39)$. New methods in paleoecology are also beginning to provide novel data on floral and faunal changes through time within mountain ecosystems (40), and modern genomics allow us to "travel through time" to understand population dynamics over millions of years (e.g. by estimating effective population size and timing of genetic bottlenecks).

The global pattern of hyperdiverse tropical mountains likely reflects the differentiation of small, spatially isolated populations combined with the long-term maintenance of these populations. The ICARUS space project has the potential to document rare, longer-distance dispersal of otherwise sedentary tropical species between such isolated populations. Likewise, most of our conceptual framework for community structure and evolutionary dynamics is based 
on studies from temperate species and habitats, and very little is known about how tropical mountain species arise and persist, and when and why they may face extinction. Understanding extinctions is crucially important in a world of change in land-use and climate, now facing a global biodiversity crisis.

Climate change will shift treelines and is already driving mountain species upslope (41), including the vegetation zones and plant taxa described by von Humboldt in the Andes (42-43). The consequences for species already adapted to the colder conditions near mountaintops are uncertain. The complex configuration of mountain climates means that current models, based on simple upslope shifts of species, are insufficient and potentially misleading. Process-based models at fine spatial scales, explicitly incorporating micro-climate variation within similar elevational bands and movement between isolated habitat patches, are urgently needed to predict the future of mountain species under conditions of global environmental change. 


\section{References:}

1. C. Rahbek et al., Building mountain diversity: evolutionary and geological processes (Submitted review ms to Science).

2. C. Rahbek, C. R. Graves, Multiscale assessment of patterns of avian species richness. Proc. Natl. Acad. Sci. U.S.A. 98, 4534-4539 (2001).

3. W. Jetz, C. Rahbek, Geographic range size and determinants of avian species richness. Science 297, 1548-1551 (2002).

4. C. Rahbek, N. J. Gotelli, R. K. Colwell, G. L. Entsminger, T. F. L. V. B. Rangel, C. R. Graves, Predicting continental-scale patterns of bird species richness with spatially explicit models. Proc. R. Soc. B 274, 165-174 (2007).

5. A. Antonelli et al., Geological and climatic influences on mountain biodiversity. Nat. Geosci. 11, 718-725 (2018).

6. B. G. Holt et al., An update of Wallace's zoogeographic regions of the world. Science 339, 74-78 (2013).

7. C. Rahbek, M. K. Borregaard, B. Hermansen, D. Nogués-Bravo, J. Fjeldså, Definition and description of the Montane Regions of the World. https://macroecology.ku.dk/resources/Mountain_Regions (2019).

8. H. Balslev, R. Valencia, G. Paz y Mino, H. Christensen, I. Nielsen, in Forest biodiversity in North, Central and South America, and the Caribbean: Research and monitoring, F. Dallmeier, J. A. Comiskey, Eds. (UNESCO, Paris, 1998), pp. 585-594.

9. I.R. McFadden et al., Temperature shapes opposing latitudinal gradients of plant taxonomic and phylogenetic $\beta$ diversity. Ecol. Lett. 22, 1126-1135 (2019)

10. M. L. Rosenzweig, Species diversity in space and time (Cambridge University Press, Cambridge, 1995).

11. C. Rahbek, The elevational gradient of species richness: a uniform pattern? Ecography 18, 200-205 (1995).

12. C. Rahbek, The relationship among area, elevation, and regional species richness in Neotropical birds. Am. Nat. 149, 875-902 (1997).

13. J. Beck et al., Elevational species richness gradients in a hyperdiverse insect taxon: a global meta-study on geometrid moths. Global Ecol. Biogeogr. 26, 412-424 (2017).

14. N. Myers, R.A. Mittermeier, C.G. Mittermeier, G.A.B. da Fonseca, J. Kent, Biodiversity hotspots for conservation priorities. Nature, 403, 853-858 (2000).

15. D. J. Currie, Energy and large-scale patterns of animal- and plant-species richness. Am. Nat. 137, 27-49 (1991).

16. B. A. Hawkins et al., Energy, water, and broad-scale geographic patterns of species richness. Ecology 84, 31053117 (2003).

17. R. Field, E. M. O’Brien, R. J. Whittaker, Global models for predicting woody plant richness from climate: development and evaluation. Ecology 86, 2263-2277 (2005).

18. W. Barthlott, J. Mutke, M. D. Rafiqpoor, G. Kier, H. Kreft, Global centers of vascular plant diversity. Nova Acta Leopold. 92, 61-83 (2005).

19. S. R. Connolly, S. A. Keith, R. K. Colwell, C. Rahbek, Process, mechanism, and modeling in macroecology. Trends Ecol. Evol. 32, 835-844 (2017).

20. T. F. Rangel et al., Modeling the ecology and evolution of biodiversity: biogeographical cradles, museums, and graves. Science 361, eaar5452 (2018).

21. R. G. Davies et al., Topography, energy and the global distribution of bird species richness. Proc. R. Soc. B 274, 1189-1197 (2007).

22. H. Kreft, W. Jetz, Global patterns and determinants of vascular plant diversity. Proc. Natl. Acad. Sci. U.S.A. 104, 5925-5930 (2007).

23. C. Körner, W. Jetz, J. Paulsen, D. Payne, K. Rudmann-Maurer, E. M. Spehn, A global inventory of mountains for bio-geographical applications. Alp. Bot. 127, 1-15 (2017).

24. J. Fjeldså, E. Lambin, B. Mertens, Correlation between endemism and local ecoclimatic stability documented by comparing Andean bird distributions and remotely sensed land surface data. Ecography 22, 63-78 (1999).

25. C. Hughes, R. Eastwood, Island radiation on a continental scale: exceptional rates of plant diversification after uplift of the Andes. Proc. Natl. Acad. Sci. U.S.A. 103, 10334-10339 (2006).

26. C. Hoorn, A. Perrigo, A. Antonelli, Eds. Mountains, climate and biodiversity (Wiley, 2018).

27. J. Fjeldså, R. C. K. Bowie, C Rahbek, The role of mountain ranges in the diversification of birds. Annu. Rev. Ecol. Evol. Syst. 43, 249-265 (2012).

28. C. Kröner, The use of 'altitude' in ecological research. Trends Ecol. Evol 22, 569-574 (2007). 
29. G. C. Stevens, The elevational gradient in altitudinal range: an extension of Rapoport's latitudinal rule to altitude. Am. Nat. 140, 893-911 (1992).

30. C. M. McCain, Elevational gradients in diversity of small mammals. Ecology 86, 366-372 (2005).

31. A. von Humboldt, A. Bonpland, Essay on the geography of plants. Reprint, translated by Sylvie Romanowski, edited with an introduction by S. T. Jackson (The University of Chicago Press, Chicago, 2009).

32. C. Körner, Mountain biodiversity, its causes and function. Ambio 13, 11-17 (2004).

33. W.-P. Chan, I.-C Chen, R. K. Colwell, W.-C. Liu, C.-y Huang, S.-F. Shen, Seasonal and daily climate variation have opposite effects on species elevational range size. Science 351, 1437-1439 (2016).

34. R. Ohlemüller et al., The coincidence of climatic and species rarity: high risk to small-range species from climate change. Biol. Lett. 4, 568-572 (2008).

35. D. A. Fordham, S. C. Brown, T. M. L. Wigley, C. Rahbek, Cradles of diversity are unlikely relics of regional climate stability. Curr. Biol. 29, R356-R357 (2019).

36. D. H. Janzen, Why mountain passes are higher in the tropics. Am. Nat. 101, 233-249 (1967).

37. N. L. Payne, J. A. Smith, An alternative explanation for global trends in thermal tolerance. Ecol. Lett. 20, 70-77 (2017).

38. G. R. Graves, Linearity of geographic range and its possible effect on the population structure of Andean birds. Auk 105, 47-52 (1988).

39. P. B. Holden, N. R. Edwards, T. F. Rangel, E. B. Pereira, G. T. Tran, R. D. Wilkinson, PALEO-PGEM v1.0: A statistical emulator of Pliocene-Pleistocene climate. Geosci. Mod. Dev. Discuss., gmd-2018-242 (2018).

40. A. Woutersen et al., A novel approach to study the morphology and chemistry of pollen in a phylogenetic context, applied to the halophytic taxon Nitraria L.(Nitrariaceae). PeerJ 6, e5055 (2018).

41. M. J. Steinbauer et al., Accelerated increase in plant species richness on mountain summits is linked to warming. Nature 556, 231-234 (2018).

42. N. Morueta-Holme, K. Engemann, P. Sandoval-Acuña, J. D. Jonas, R. M. Segnitz, J.-C. Svenning, Strong upslope shifts in Chimborazo's vegetation over two centuries since Humboldt. Proc. Natl. Acad. Sci. 112, 12741-12745 (2015).

43. P. Moret, P. Muriel, R. Jaramillo, O. Dangles, Humboldt's Tableau Physique revisited. Proc. Natl. Acad. Sci. U. S. A., 201904585 (2019).

44. M. New, M. Hulme, P. Jones, Representing twentieth-century space-time climate variability. Part I: Development of a 1961-90 mean monthly terrestrial climatology. J. Clim. 12, 829-856 (1999).

45. M. Zhao, S. W. Running, Drought-induced reduction in global terrestrial net primary production from 2000 through 2009. Science 329, 940-943 (2010).

46. Earth Resources Observation and Science Center/U.S. Geological Survey/U.S. Department of the Interior. USGS 30 ARC-second Global Elevation Data, GTOPO30. Research Data Archive at the National Center for Atmospheric Research, Computational and Information Systems Laboratory (1997). http://rda.ucar.edu/datasets/ds758.0/.

47. A. K. Johnston, A. Henfrey, "Geographical distribution of indigenous vegetation. The distribution of plants in a perpendicular direction in the torrid, temperate and frigid zones, with indications of the mean temperature of the year and of the coldest and warmest month" in The physical atlas of natural phenomena (William Blackwood \& Sons, Edinburgh \& London, ed. 2, 1854), P1. 25.

\section{ACKNOWLEDGMENTS}

Funding: All authors wish to thank the Danish National Research Foundation for its support of the Center for Macroecology, Evolution and Climate, CMEC, (DNRF96). C.R. was funded by a Villum Investigator grant (no. 25925) from The Villum Foundation; M.K.B. and N. M-H. were each supported by an Individual Fellowship under the Marie Sklodowska-Curie grantagreement (no. 707968 and no. 746334, respectively); Author contributions: C.R. and J.F. designed the CMEC mountain research program. C.R. and M.B.K. coordinated the work, performed all analyses and led the writing with contributions from all coauthors. The authors declare no conflicts of interest. 
FIGURES

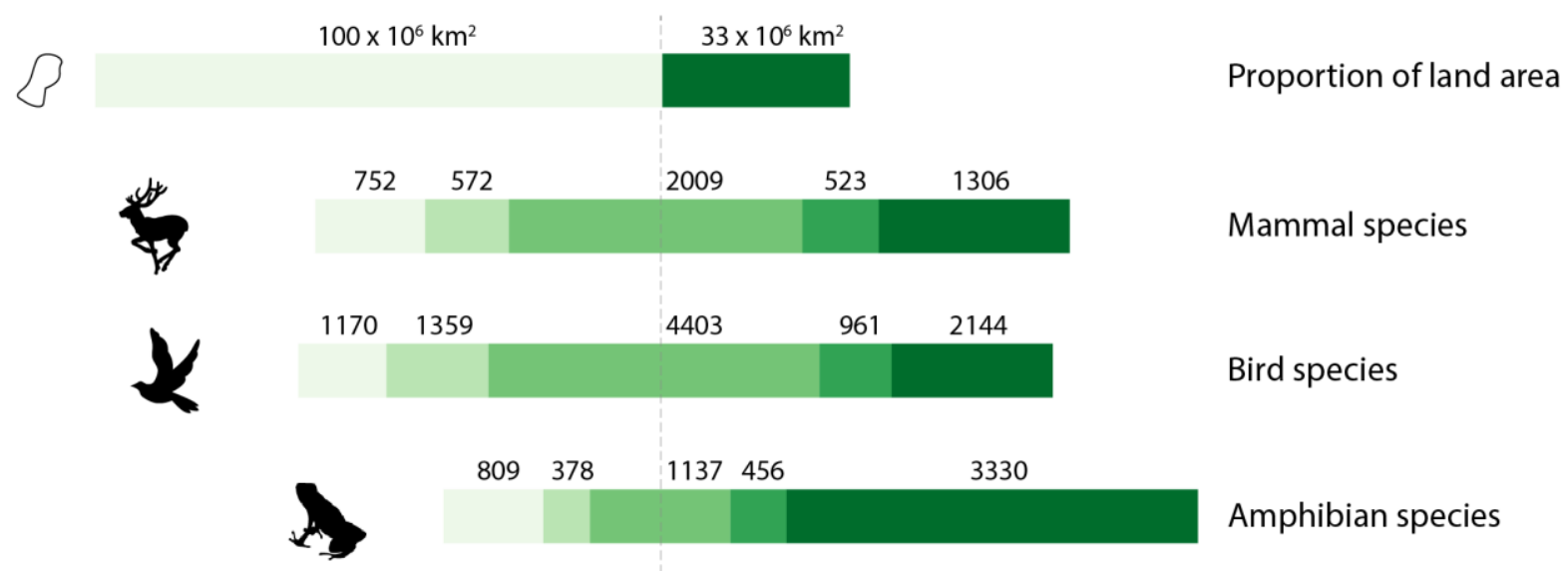

Proportion associated with:

lowlands $\square$ mountains

Proportion of species' range in mountains and lowlands:

$>=90 \%$ low $\quad>=75 \%$ low both $\square=75 \%$ mountain $\square>=90 \%$ mountains

Fig. 1. The importance of Mountain Regions for global biodiversity, as exemplified by vertebrate species. Mountain Regions (including adjacent lowland foothills) host roughly $87 \%$ of terrestrial global biodiversity (all color bars except for the lightest), despite constituting only $25 \%$ of the world's land area (Antarctica excluded). We define a "mountain endemic" as any species with 90\% of its distribution in Mountain Regions (i.e., the darkest green bar). The dashed line separates species that have most of their range in lowlands (left of the line) from mountain species (right of the line). "Both" refers to any species equally present in mountains and 10 lowlands, with 25-75\% of its range found in Mountain Regions. Proportions were calculated by overlaying the 134 Mountain Regions of the world (7) with the global distributions of vertebrate species, using the $1^{\circ}$ latitude $\mathrm{x} 1^{\circ}$ longitude distribution data of Holt et al. (6). See Fig. 3 for the geographical placement and extent of the Mountain Regions (7). 



Fig. 2.

Species richness, topography, and how well global statistical models explain the pattern of species richness. A. The global pattern of vertebrate richness (birds, mammals, and amphibians) for all land areas (both lowland and highland), superimposed on a hill-shade map showing topographic relief. B. The residuals (in units of number of species) from a standard linear regression of total richness on temperature, precipitation (1961-1990 climate from 44) and Wallace realms, as defined by Holt et al. (6), at a resolution of $1^{\circ}$ latitude $\mathrm{x} 1^{\circ}$ longitude $\left(\mathrm{r}^{2}=\right.$ $0.61)$. 

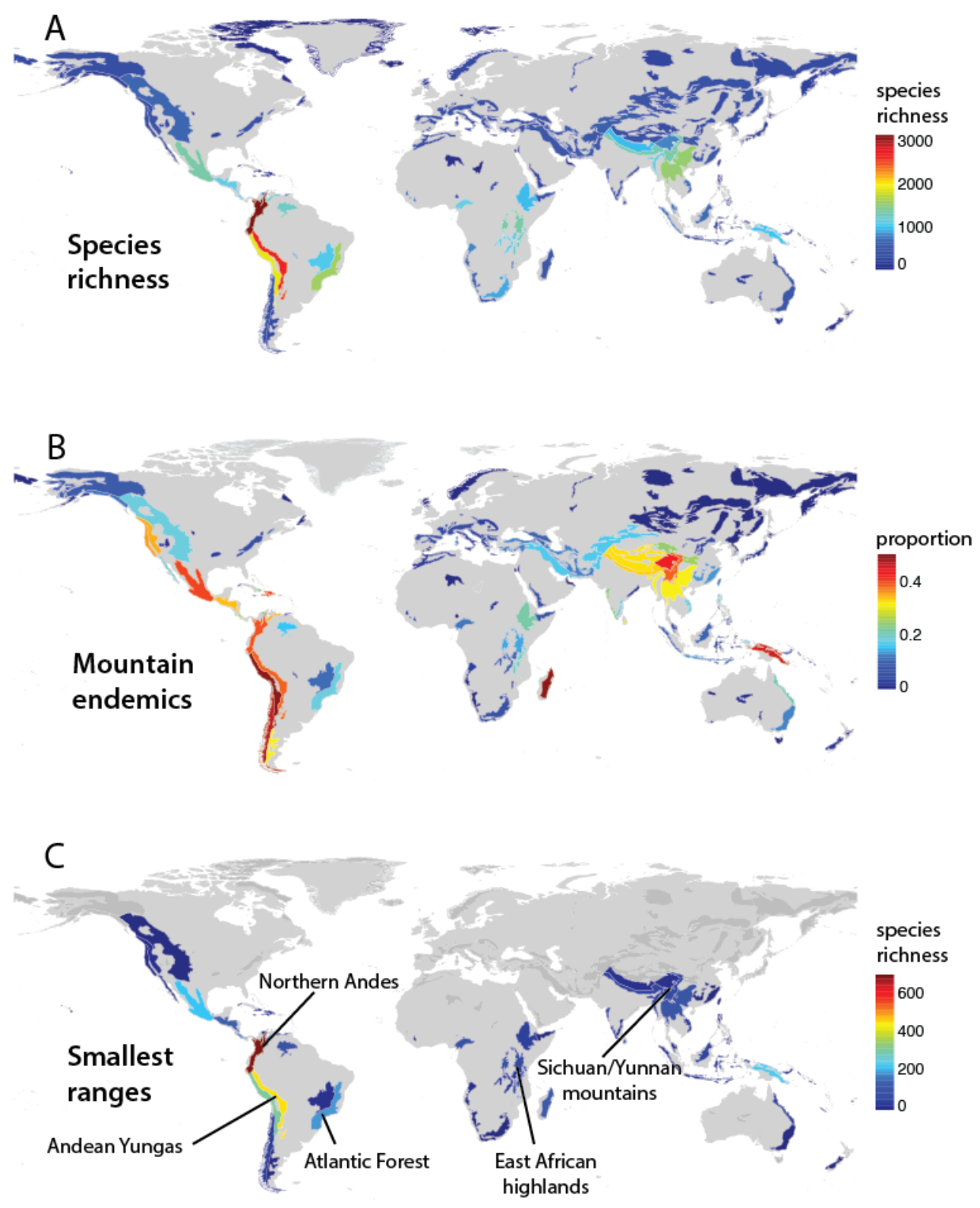

Fig. 3. Global patterns in key aspects of mountain diversity. A. Species richness is the total number of amphibian, mammal, and bird species ranges overlapping each Mountain Region. B. The proportion of species that are mountain endemics, defined as species with at least $90 \%$ of their occupied grid cells overlapping Mountain Regions (the darkest green bar in Fig. 1). C. The richness of small-ranged species, defined as the $25 \%$ of species with the smallest geographic ranges. Distribution data are from Holt et al. (6) and definition of Mountain Regions from Rahbek et al. (7). 

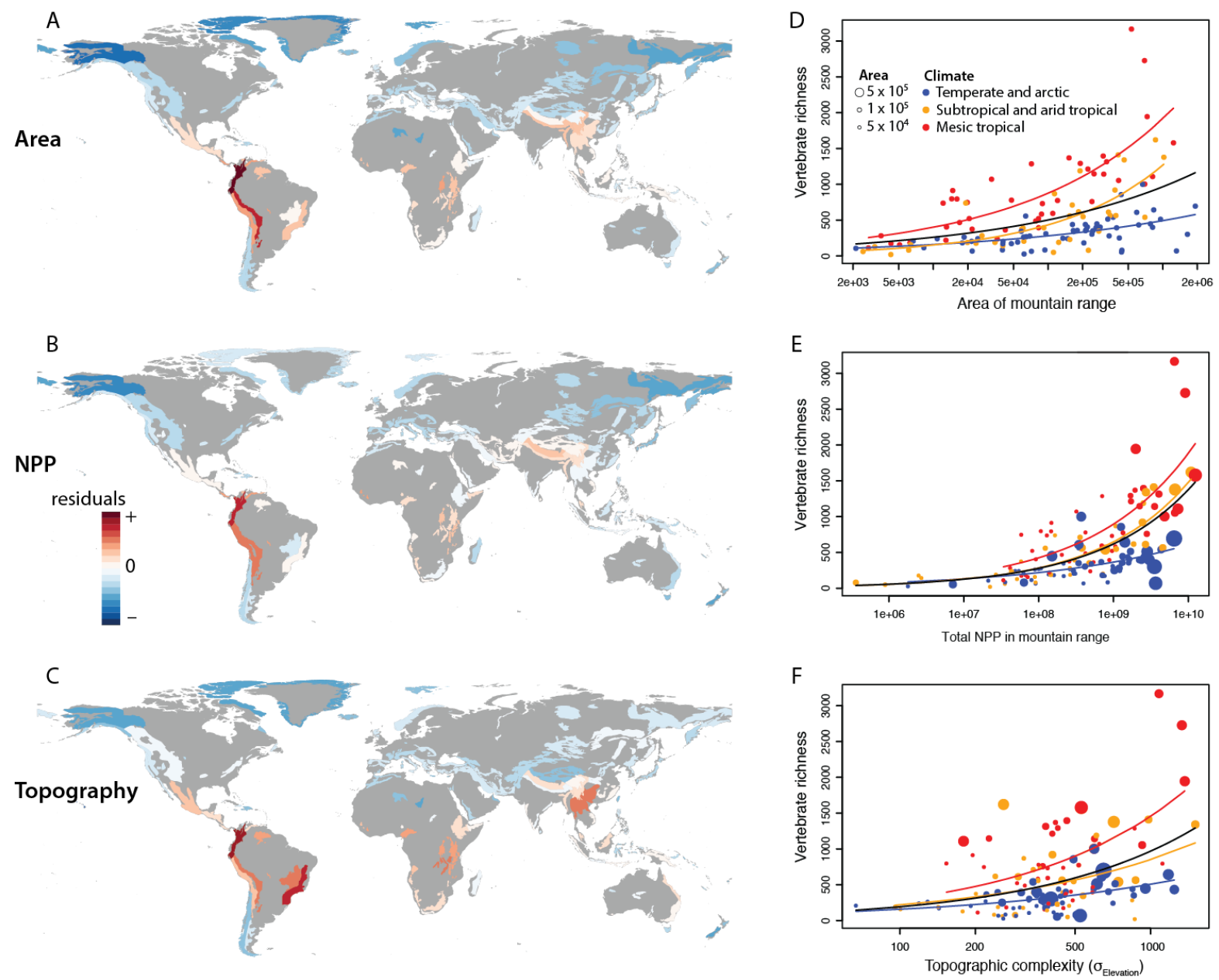

Fig. 4. Explanatory factors for mountain diversity. A-C. Spatial distribution of deviance residuals from Poisson-error regressions of species richness against area (A), Net Primary Productivity (data from 45) (B), and topographic complexity (standard deviation of $1 \mathrm{~km} 2$ elevation values; data from 46) (C) of Mountain Regions. D-F. Correlates of species richness, for area (D, from map A), Net Primary Productivity (E, from map B), and topographic complexity (E, from map C). Area (indicated by symbol size) is included in statistical models for E and F, but, for clarity, is not included in trend lines. All relationships and all interactions among variables are statistically significant (7). 

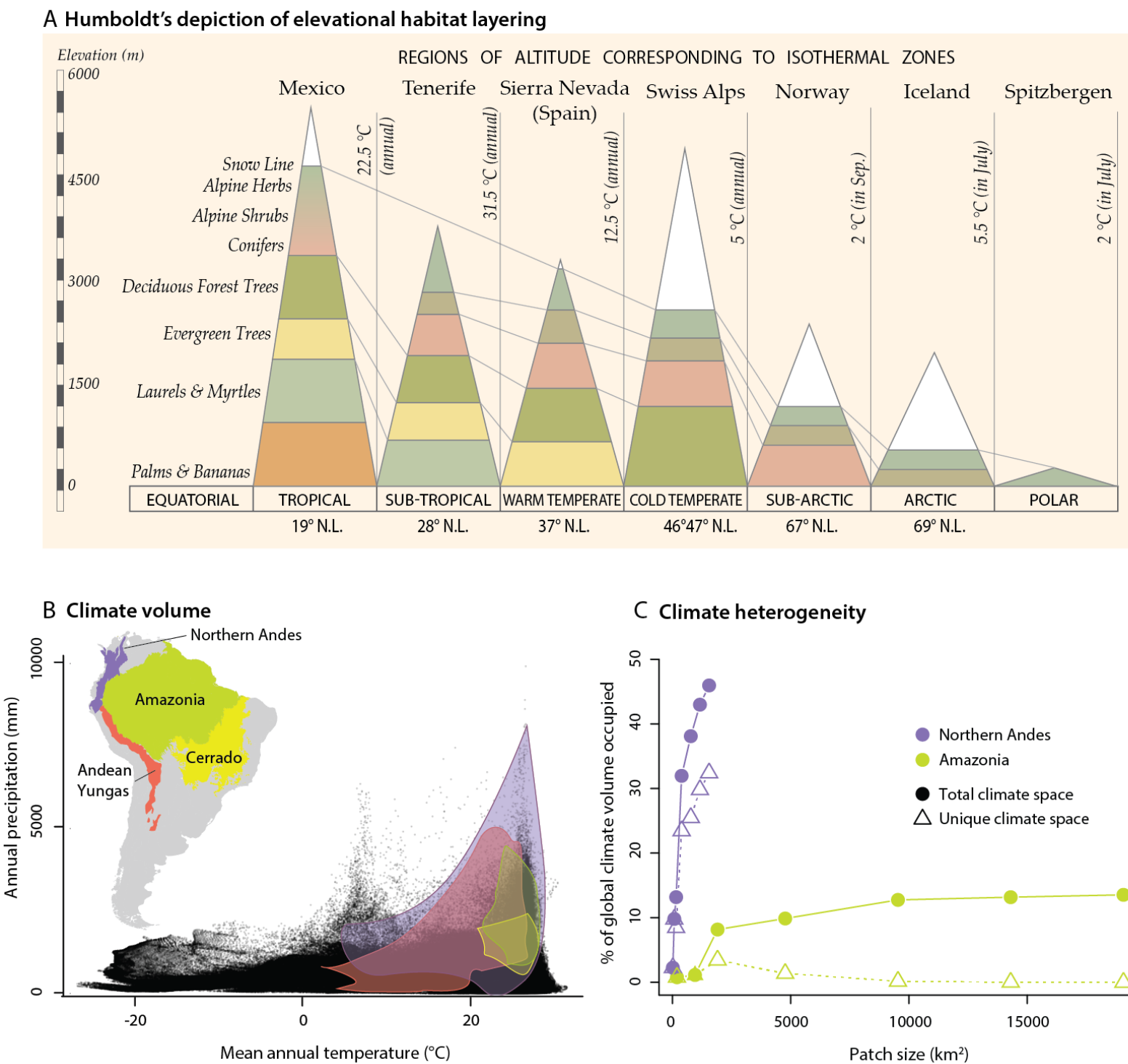

\section{Climate heterogeneity}

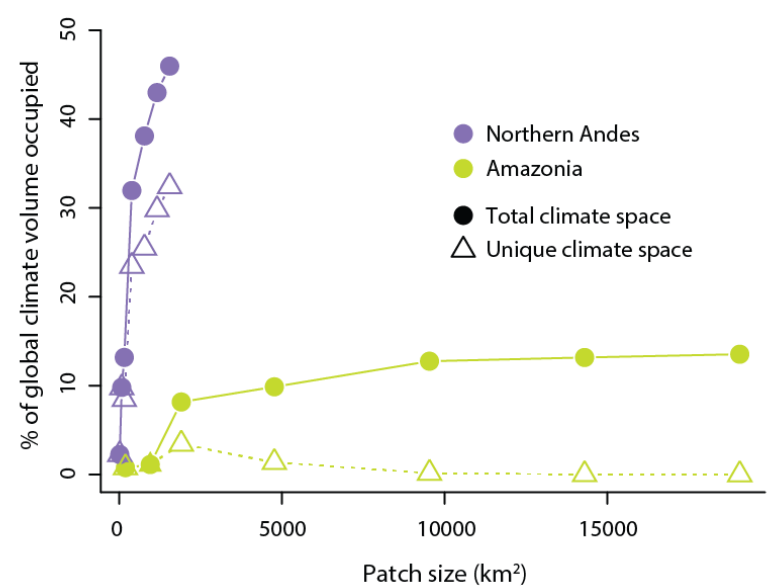

Fig. 5. Mountain climates. A. A schematic depiction of von Humboldt's classical diagram (from 47), illustrating the elevational zonation of mountains, with the implication that a tropical mountain may contain all the climatic zones of a single hemisphere. B. The climate spaces of particular Mountain Regions (Northern Andes, purple, and the Andean Yungas, red) encompass a large proportion of all climate space on Earth (black dots) and are disproportionately larger than the climate space of neighboring lowland regions (Amazonia, green, and the Cerrado, yellow). C. The tight packing of mountain climates illustrated by the rapid increase of total climate volume covered with patch area in the Northern Andes. 